\title{
Toothache as the initial symptom of plasma cell myeloma
}

\author{
Tobias Wehrhahn ${ }^{1}$, Mario Bargetzi ${ }^{1}$, Carlos Buitrago-Tellez ${ }^{2}$, Gianni Cantelmi ${ }^{3}$
}

Correspondence: Dr. Tobias Wehrhahn

Email: tobias.wehrhahn@ksa.ch

\author{
'Department of Medical Oncology, Hematology and \\ Transfusion Medicine, Cantonal Hospital Aarau, Aarau, \\ Switzerland, \\ 2Department of Radiology, Spital Zofingen, Zofingen, \\ Switzerland, \\ ${ }^{3}$ Private Practice, Zofingen, Switzerland
}

\section{ABSTRACT}

Patients with plasma cell myeloma may initially present to their dentists or dental surgeons with toothache, loose teeth, or gingival masses. An X-ray of the jaw can reveal osteolyses. In addition, accumulation of monoclonal light chains in AL-amyloidosis can lead to macroglossia. It is prudent that the dentist or dental surgeon recognizes the underlying disease and refers the patient to the oncologist or hematologist for further workup to prevent the complications of plasma cell myeloma such as renal impairment, fractures, bone pain, infections, hypercalcemia, anemia, or heart failure. Another area where the dentist or dental surgeon is involved with patients suffering from plasma cell myeloma is prevention and therapy of osteonecrosis of the jaw, occurring after administration of bisphosphonates or denosumab for osteolytic bone disease. The case report presented here shows a patient complaining of toothache for whom recognition of a systemic disease by the dentist led to the diagnosis of plasma cell myeloma, highlighting the need for interdisciplinary cooperation. As recent years have seen many changes in the management of patients with plasma cell myeloma, an update for dentists and dental surgeons is warranted.

Key words: AL-amyloidosis, bisphosphonates, denosumab, dental surgeon, dentist, macroglossia, osteolysis, osteonecrosis of the jaw, plasma cell myeloma, toothache

\section{INTRODUCTION}

Plasma cell myeloma, as multiple myeloma is now termed in the new WHO 2017 classification, is the second most frequent hematological malignancy with an incidence of 6/100,000 persons per year in Europe and the USA. ${ }^{[1,2]}$ Neoplastic proliferation of the plasma cells produces a monoclonal immunoglobulin (IgG, IgA, and rarely IgM, IgD) or light chain (kappa or lambda). ${ }^{[1,2]}$ More than $10 \%$ of clonal plasma cells in the bone marrow define plasma cell myeloma, whereas $<10 \%$ of plasma cells without further symptoms are considered monoclonal gammopathy of undetermined significance (M-GUS). ${ }^{[3]}$ M-GUS

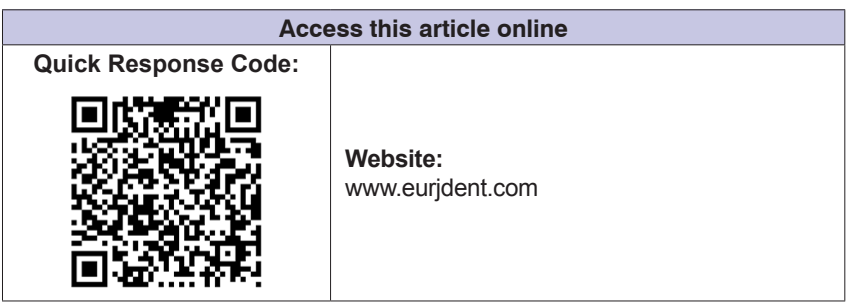

progresses to plasma cell myeloma at a rate of $1 \%$ per year and all patients with plasma cell myeloma had a preexisting, although often not recognized M-GUS. ${ }^{[3]}$ Asymptomatic plasma cell myeloma lacks symptoms defining symptomatic disease such as hyperCalcemia, Renal insufficiency, Anemia, and Bone disease, also termed CRAB criteria. These criteria warrant immediate treatment of the disease. ${ }^{[4]}$ In recent years, additional criteria to start treatment have been identified such as $>60 \%$ plasma cells in the bone marrow, a ratio $>100$ for involved over uninvolved light

This is an open access journal, and articles are distributed under the terms of the Creative Commons Attribution-NonCommercial-ShareAlike 4.0 License, which allows others to remix, tweak, and build upon the work non-commercially, as long as appropriate credit is given and the new creations are licensed under the identical terms.

For reprints contact: reprints@medknow.com

How to cite this article: Wehrhahn T, Bargetzi M, Buitrago-Tellez C, Cantelmi G. Toothache as the initial symptom of plasma cell myeloma. Eur J Dent 2018;12:443-5.

DOI: $10.4103 /$ ejd.ejd_412_17 
chains in the free light chain assay, and $>1$ focal lesion in a whole-body magnetic resonance imaging (MRI) of the bones. ${ }^{[3]}$ Radiologic survey of all bones has also seen a transition from a skeletal X-ray to whole-body low-dose computed tomography (CT) scan, whole-body MRI, or positron emission tomography CT scan allowing to better characterize the extent of the disease and finding extramedullary involvement of myeloma. ${ }^{[3]}$ Introduction of new antimyeloma drugs with proteasome inhibitors, immune modulators, antimyeloma antibodies, and their combinations has changed the outcome for patients suffering of plasma cell myeloma to the better. ${ }^{[4]}$

In up to $30 \%$ of cases, manifestations of myeloma can affect the oral cavity or the facial bones. Toothache, loose teeth, and gingival masses can be the first sign of the disease, leading the patient to the dentist or dental surgeon. ${ }^{[5-7]}$ Our case report points out the necessity of interdisciplinary cooperation.

\section{CASE REPORT}

In October 2015, a 60-year-old male patient went to see his dentist due to toothache, increasing dysesthesia, and pain of the chin and the right mandible. These symptoms were accompanied by a slight reduction in physical fitness and some dyspnea. The dentist performed a dental cone-beam computed tomography (digital volume tomography), showing osteosclerotic lesions in the right mandible [Figure 1]. For further workup to distinguish infection from malignancy, an MRI of the skull was carried out revealing multifocal bone marrow infiltration in the whole mandible and the left parietal region [Figure 2]. With these findings, the dentist referred the patient to an oncologist.

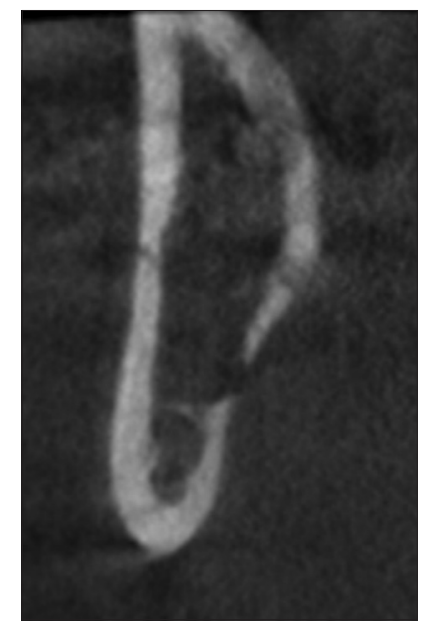

Figure 1: Digital volume tomography with osteosclerotic lesions in the right mandible
Further workup with laboratory analyses showed a monoclonal gammopathy IgA lambda in the serum electrophoresis and immunofixation and free lambda light chains in the free light chain assay. Forty-five percent of monoclonal plasma cells were found in the bone marrow. Cytogenetics of the plasma cells of the bone marrow indicated poor risk constellation with translocation $t(4 ; 14)$, deletion del13, gain $+1 q$ and $+16 q$. A whole-body MRI demonstrated additional osteolytic lesions throughout the body. With consideration of serum $\beta 2$-microglobulin and serum albumin diagnosis of symptomatic plasma cell myeloma, IgA lambda with an International Scoring System (ISS) I was made. Because of the poor cytogenetic risk profile mentioned above, revised ISS (R-ISS) for the patient was III, indicating a significant reduction of the median 5-year overall survival (R-ISS I: $82 \%$; R-ISS III: $40 \%) .{ }^{[8]}$ As the patient complained about dyspnea and having free light chains, a fine-needle aspiration of the abdominal fat was performed showing AL-amyloidosis. However, further workup did not reveal cardiac or renal involvement of amyloidosis. Macroglossia as another symptom of amyloidosis was not present.

Induction treatment with bortezomib, cyclophosphamide, and dexamethasone was initiated leading to a very good partial remission. After successful stem cell collection, two cycles of high-dose chemotherapy with melphalan and autologous stem cell transplantation were applied as consolidation. Maintenance therapy with lenalidomide was added in the course. However, only 3 months on maintenance, the patient progressed with new extraosseous lesions. The second-line treatment with carfilzomib, lenalidomide, and dexamethasone (KRD) was started. Because of ongoing clinical and radiographic progression after

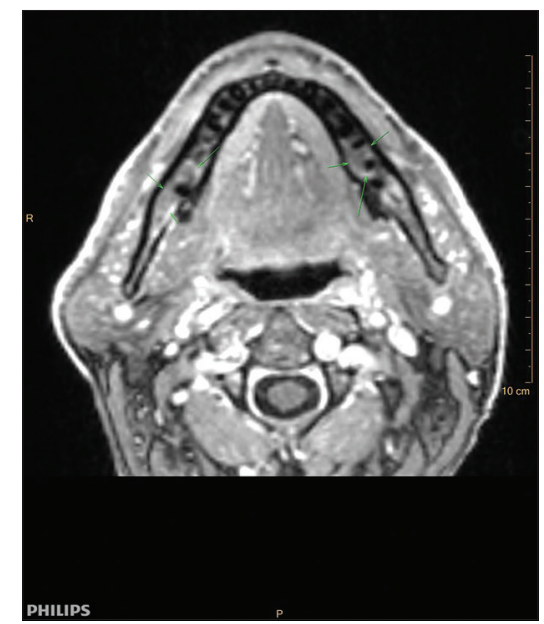

Figure 2: Magnetic resonance imaging of the skull: Multifocal bone marrow infiltration in the mandible 
three courses of KRD, treatment was changed to the antibody daratumumab. Unfortunately, myeloma did not respond to this new treatment. After approximately 2 years since the diagnosis of the plasma cell myeloma, the patient is facing the start of his fifth-line treatment with pomalidomide and dexamethasone, underlining the very aggressive course of the disease in this patient. Besides antineoplastic therapy, our patient received a supportive antiresorptive treatment with pamidronate. Symptomatic radiation therapy of the most symptomatic osseous sites was offered on demand.

\section{DISCUSSION}

Plasma cell myeloma is characterized by neoplastic proliferation of plasma cells producing a monoclonal immunoglobulin and/or light chains often accompanied by osteolytic bone lesions. ${ }^{[1,2]} \mathrm{Up}$ to $30 \%$ of myeloma patients show a lytic involvement of the jaws. Toothache as the presenting symptom may occur in up to $15 \%$ of patients. Other signs of myeloma involving the oral cavity can be oral or facial pain, loose teeth, paresthesia, hemorrhage, fracture, root resorption, and gingival masses. In AL-amyloidosis, a deposition disease of immunoglobulin light chains, macroglossia can be observed. Typical punched out osteolytic lesions are more frequent in the mandible than in the maxilla, possibly due to higher hematopoietic activity in these areas. They occur more frequently in the posterior regions of the mandible, the ramus, and condylar process. ${ }^{[5-7]}$

It is important that the dentist or dental surgeon recognizes these findings as a part of a systemic disease and refers the patient to the oncologist or hematologist for further workup. As new treatment options of plasma cell myeloma have emerged over the last years, ${ }^{[4]}$ rapid diagnosis and initiation of therapy are emphasized to prevent the complications of plasma cell myeloma such as renal impairment, fractures, bone pain, infections, hypercalcemia, anemia, or heart failure. In addition to symptoms and clinical signs of plasma cell myeloma in the oral cavity, the dentist or dental surgeon is called on for dental revision, and restoration before treatment with bisphosphonates or denosumab is initiated to reduce the risk of osteonecrosis of the jaw. Because of the risk of osteonecrosis of the jaw, patients should be advised to focus on dental hygiene. Invasive dental procedures should be done with caution, ideally before the start of bisphosphonates. ${ }^{[2,7]}$

This case report shows the important interaction between the dentist and the oncologist or hematologist in caring for patients with plasma cell myeloma.

\section{Declaration of patient consent}

The authors certify that they have obtained all appropriate patient consent forms. In the form the patient(s) has/have given his/her/their consent for his/her/their images and other clinical information to be reported in the journal. The patients understand that their names and initials will not be published and due efforts will be made to conceal their identity, but anonymity cannot be guaranteed.

\section{Financial support and sponsorship}

Nil.

\section{Conflicts of interest}

There are no conflicts of interest.

\section{REFERENCES}

1. McKenna RW, Kyle RA, Kuehl WM, Harris NL, Coupland RW, Fend F. Plasma cell neoplasms. In: Swerdlow SH, Campo E, Harris NL, Jaffe ES, Pileri SA, Stein H, et al., editors. WHO Classification of Tumours of Haematopoietic and Lymphoid Tissues. Revised $4^{\text {th }}$ ed. Lyon: IARC; 2017.

2. Röllig C, Knop S, Bornhäuser M. Multiple myeloma. Lancet 2015;385:2197-208.

3. Rajkumar SV, Dimopoulos MA, Palumbo A, Blade J, Merlini G, Mateos MV, et al. International myeloma working group updated criteria for the diagnosis of multiple myeloma. Lancet Oncol 2014;15:e538-48.

4. Samaras P, Bargetzi M, Betticher DC, Duchosal MA, Heim D, Hess U, et al. Current status and updated recommendations for diagnosis and treatment of plasma cell myeloma in Switzerland. Swiss Med Wkly 2015;145:w14100.

5. Shah A, Latoo S, Ahmad I. Multiple myeloma and dentistry. In: Gupta A, editor. Multiple Myeloma - An Overview; 2012. Available from: https:/www.intechopen.com/books/multiple-myeloma-an-overview/ multiple-myeloma-and-dentistry. [Last accessed on 2018 Jul 15].

6. Shah A, Ali A, Latoo S, Ahmad I. Multiple myeloma presenting as gingival mass. J Maxillofac Oral Surg 2010;9:209-12.

7. Ramaiah KK, Joshi V, Thayi SR, Sathyanarayana P, Patil P, Ahmed Z, et al. Multiple myeloma presenting with a maxillary lesion as the first sign. Imaging Sci Dent 2015;45:55-60.

8. Palumbo A, Avet-Loiseau H, Oliva S, Lokhorst HM, Goldschmidt H, Rosinol L, et al. Revised international staging system for multiple myeloma: A report from international myeloma working group. J Clin Oncol 2015;33:2863-9. 